\title{
Investigación exploratoria sobre migración de mujeres de Somoto (Nicaragua) a San Sebastián (España)
}

\author{
José Luis González Miranda, S.J.*
}

Recibido: octubre de 2011 / Aceptado: noviembre de 2011

El presente artículo analiza la migración de mujeres de Somoto (Madriz, Nicaragua) a San Sebastián (Guipúzcoa, España), fenómeno iniciado a raíz del hermanamiento de Somoto con la ciudad de Lasarte, después del paso del huracán Mitch. El crecimiento acelerado de esta población migrante hacia España, así como la feminización del fenómeno, caracterizan este hecho que ha marcado al municipio de Somoto en la última década. En el registro de extranjeros residentes en España, la población nicaragüense creció un 53.3\% entre junio de 2010 y junio de 2011. En esta última fecha las mujeres nicaragüenses son el $73.5 \%$ del total de población nicaragüense residente en España. Suponemos que la migración irregular ofrecerá cifras parecidas. Esta feminización acompaña a la globalización de las tareas de cuidado, lo que es denominado por otros autores como "la mundialización del amor materno". Para cuidar niños, ancianos y hogares en San Sebastián, las mujeres somoteñas dejan muchos de sus hogares a cargo de abuelas, tías e hijas, a veces menores de edad. Los receptores de remesas son también mayoritariamente mujeres. Por medio de estas cadenas globales de cuidado asistimos al "robo del cariño" más que a la redistribución de las tareas de cuidado entre hombres y mujeres. Se explora aquí el impacto que este fenómeno migratorio provoca en las migrantes, en sus familias, y en el municipio de Somoto, para sugerir políticas públicas y recomendaciones que incidan en la mejora de las condiciones sociales de esta población migrante y de sus familias.

Palabras clave: Migración / mujeres / Nicaragua / España / impacto

* Investigador del Servicio Jesuita para Migrantes - Nicaragua. Universidad Centroamericana, edificio C, Managua. Correo electrónico: jolugomi@jesuits.net 


\section{Introducción}

De Somoto es el cantautor Carlos Mejía Godoy. En una de sus canciones, una anciana mujer que está muriendo lejos de su tierra, implora: "Tráeme un puñado de esa santa tierra, que quiero besarla para bien morir". En ese canto -La viejecita de Mozambique- se alaba el amor de los migrantes a la patria añorada y la importancia del que muere "soñando volver a ella".

Esta investigación se centra en mujeres migrantes de Somoto (Madriz, Nicaragua) a San Sebastián (Guipúzcoa, España). Se trata de un flujo migratorio creciente que ha salido a la luz pública a raíz de unas declaraciones del viceministro de Gobernación, Carlos Nájar, en julio de 2008, en El Nuevo Diario, en las que afirmaba que "en Somoto hay casi dos mil mujeres que han emigrado a España" (Sirias, 2008). Fueron declaraciones dadas durante la inauguración de un taller sobre la trata de personas. La palabra "esclavas" asomaba en el titular del diario, y no tardó la Embajada de España en interesarse por el tema, así como la Organización Internacional para las Migraciones (OIM) y Save the Children. Esta organización ya venía trabajando en intervención psicosocial para víctimas de trata de personas en Chinandega (junto a la OIM) y en mapeos geográficos y sociales en Somoto sobre explotación sexual comercial y niñez trabajadora (junto con el INPRHU). Esos antecedentes explican que Save the Children y OIM sean las ejecutoras de este proyecto junto con el Servicio Jesuita para Migrantes (SJM-Nicaragua) y el Instituto Nicaragüense de Promoción Humana (INPRHU-Somoto) como contrapartes locales. Entre las entidades colaboradoras, agradecemos particularmente al Ministerio de Gobernación, el Ministerio Público, la Comisaría de la Mujer, el Ministerio de Educación, la Policía Nacional, la Alcaldía de Somoto y, muy especialmente, a la Dirección General de Migración y Extranjería (DGME).

\section{Objetivo y metodología de la investigación}

La investigación pretende caracterizar la migración de mujeres de Somoto a San Sebastián y obtener una serie de elementos para realizar un análisis de la situación que nos permita proponer acciones concretas en un futuro. Es decir, el impacto que este fenómeno migratorio provoca en las migrantes, en sus familias y en el municipio de Somoto, es lo que se intenta investigar para sugerir políticas públicas y recomendaciones que incidan en la mejora de las condiciones sociales de esta población.

La población investigada ha sido la que tiene familiares en España, así como la que ya ha regresado. Se realizaron, en colaboración con la DGME, 200 encuestas a familias de migrantes y mujeres migrantes. Así mismo, se desarrollaron cuatro grupos focales (dos con adultos, y dos con niños, niñas y adolescentes) y cuatro entrevistas con informantes clave de instituciones locales, a los que nos referiremos según la siguiente nomenclatura: 
EC 1: Entrevista clave con Ivonne Castillo Guillén, responsable de agencia de viajes.

EC 2: Entrevista clave con Marcio Rivas, ex alcalde de Somoto.

EC 3: Entrevista clave con Randolf Acuña, delegado departamental del Ministerio de Gobernación.

EC 4: Entrevista clave con Brenda Ferrufino, técnica del Servicio de Trámite Migratorio (SERTRAMI) de Migración.

GF 1: Grupo focal con parientes adultos de inmigrantes a España (10 de marzo de 2009)

GF 2: Grupo focal con parientes adolescentes (15 a 18 años) de inmigrantes a España (12 de marzo de 2009)

GF 3: Grupo focal con parientes adultos de inmigrantes a España (13 de marzo de 2009)

GF 4: Grupo focal con parientes niños, niñas y adolescentes (10 a 13 años) de inmigrantes a España (17 de marzo de 2009)

También se revisaron estudios sobre Somoto, investigaciones sobre asociacionismo inmigrante y sobre trabajo doméstico en España, así como documentación referente a los impactos socio-emocionales de la migración. De particular importancia han sido las noticias relativas a la migración de Somoto a España, fenómeno al que diferentes medios han dado seguimiento a raíz de las citadas declaraciones del viceministro de Gobernación. Igualmente, ha sido de gran utilidad el video-documental realizado por el INPRHU, y que forma parte del mismo proyecto investigativo.

\section{Antecedentes y contexto}

En los 474 kilómetros cuadrados del municipio de Somoto hay 35,000 habitantes distribuidos en 24 barrios urbanos y 53 comunidades. Esta población está emigrando en los últimos años a un ritmo desenfrenado. Y el destino principal hoy es España, según afirma el alcalde de Somoto, Wilson Pablo Montoya, en la entrevista realizada con él para el video-documental realizado en el marco de este proyecto.

¿Cuál es el origen de la migración somoteña a España? Todas las fuentes coinciden en señalar el origen de esta migración en el hermanamiento del municipio de Lasarte-Oria (Guipúzcoa, España) con el municipio de Somoto (Madriz, Nicaragua).

Según la responsable de una agencia de viajes (EC1), la emigración de Somoto a San Sebastián se inicia en el año 2000 por amistad de personas de Somoto con algunos cooperantes. Lo mismo afirma Brenda Ferrufino, técnica del Servicio de Tramitaciones de Migración (EC4).

El ex alcalde de Somoto, Marcio Ariel Rivas Núñez (EC2), sitúa el origen después del huracán Mitch (noviembre de 1998), siempre en referencia al hermanamiento con Lasarte. Por su parte, el Delegado Departamental del Ministerio de Gobernación, Randolf Acuña, también señala los hermanamientos como el factor desencadenante de este fenómeno en Somoto (EC3). 
Encontramos un informante que cita expresamente a la ex alcaldesa de Lasarte, Ana Urchueguía, como conexión clave en el logro del proyecto migratorio. Es el caso de un testimonio recogido en el video-documental que formó parte de esta investigación:

De ahí se me fue el otro que estaba en segundo año de ingeniería, ya no pudimos seguir, se fue y gracias a Dios doña Ana Urchueguía me lo llevó a trabajar donde el señor que donó el estadio de fútbol, y ya va a cumplir tres años de estar ahí (GF3).

Hay otros hermanamientos de Somoto con ciudades de España como Leganés, Vic o Llodio, pero es unánime la identificación de la emigración con la cooperación de Lasarte como desencadenante.

\subsection{El hermanamiento Lasarte-Somoto}

Al decir que el hermanamiento es el "factor desencadenante", hacemos referencia a que no es la causa primera. Existen otras causas más estructurales en las que este estudio no pretende profundizar pero que son comunes en sociología de la migración: empobrecimiento, falta de infraestructuras, degradación de los recursos naturales (tierra y agua) y la competencia por ellos, efecto llamada, diferencial de desarrollo, frustración psicosocial y desencanto ante una situación política ineficaz, etc. Una catástrofe natural como el huracán Mitch y una red de relaciones de amistad creada desde la solidaridad son el conducto de escape a una situación que estaba en ebullición, pero no son la causa primera del fenómeno migratorio. 
Cuadro 1. Breve historia de un hermanamiento

Aunque la población considera que el hermanamiento entre el municipio de Lasarte-Oria y el de Somoto se dio como consecuencia del huracán Mitch, parece ser que se inició un año antes, el 14 de junio de 1997, según el diario Noticias de Guipúzcoa ("Las claves del entramado...", 2011).

Sin embargo, en Noticias de Navarra (Lapitz, 2011) se vuelve a informar que la relación se inició después del Mitch a través de un dirigente sandinista que contribuyó a cambiar el destino de la ayuda que el municipio de Lasarte, cuya alcaldesa era entonces Ana Urchueguía, iba a destinar en principio a la Costa Atlántica. Algunos cooperantes fueron alojados por familias somoteñas y esto dio origen a una relación de amistad. Después se crea la Oficina de Hermanamiento de Lasarte-Oria en Somoto (OHLOS), lo que hoy es la Fundación Somoto.

En la actualidad un escándalo salpica a la ex Alcaldesa de Lasarte, acusada de haber manejado directamente los fondos de cooperación con Somoto, de haber comprado cinco fincas que ahora están a su nombre y de haber apoyado políticamente al ex alcalde de Somoto, Marcio Rivas, con el que algunos medios la unen sentimentalmente.

Hay que señalar que las acusaciones provienen del diario DEIA y del Grupo Noticias, ligados al Partido Nacionalista Vasco, opositor al Partido Socialista Vasco de Ana Urchueguía. La ex Alcaldesa ha pasado por una Comisión del Parlamento Vasco el martes 5 de abril de 2011, para explicar las acusaciones (Nagore, 2011a).

En las elecciones municipales del 22 de mayo se da en Lasarte un cambio de autoridades y éstas anuncian acciones legales contra la ex Alcaldesa bajo la acusación de enriquecimiento ilícito en la cooperación con Somoto (Nagore, 2011c).

Mientras tanto, en Nicaragua, El Nuevo Diario hace eco del escándalo (“Cooperante vasca escandaliza...", 2011). Por su parte, La Prensa informa el 25 de octubre que Ana Urchueguía ganó una demanda judicial contra el ex funcionario Mauricio Cajina Canelo por injurias y calumnias, daños y perjuicios (Aragón, 2011).

En ocasiones se invoca un principio de fraternidad universal como respuesta ética al fenómeno migratorio. En el caso que nos ocupa, el hermanamiento está ya en el origen del fenómeno. Dicho de otro modo, la multiplicación de relaciones que permite la globalización favorece que la relación movilidad humana y solidaridad vaya en doble dirección: la migración puede provocar la solidaridad, pero la solidaridad también provoca la migración. Al menos, como en este caso, ha sido un factor desencadenante.

Curiosamente, hace casi cuarenta años fue la solidaridad de un vasco la que llevó al somoteño Carlos Mejía Godoy, cantautor al que hicimos referencia al iniciar este artículo, a su primera gira en España. Se trata del sacerdote alavés Victoriano Arizti $^{1}$, a quien Carlos Mejía dedica "La viejecita de Mozambique". Pero sin duda,

1 El P. Victoriano Arizti, ligado a la JOC y a los Cursillos de Cristiandad, falleció el 30 de enero de 2009 a la edad de 83 años, después de más de 30 viajes a Nicaragua. Llegó por primera vez en 1972, según Carlos Mántica, en cuya casa conoció Victoriano a Carlos Mejía Godoy (Comunidad Señorío de Jesús, 2008). 
no son las mismas condiciones las que se dan hoy si las comparamos con aquellas giras artísticas que pusieron la música nicaragüense en los primeros lugares de las listas de éxitos en España en los años 70. Esas condiciones actuales constituyen lo que llamamos el patrón migratorio, que vamos a ver a continuación.

\subsection{Patrón migratorio}

En la migración de Somoto a Guipúzcoa estaría caracterizado un patrón migratorio desencadenado por la cooperación y desarrollado por el efecto llamada hacia una especialización en el trabajo doméstico y una consiguiente feminización.

En la construcción de ese patrón no entran en juego solamente las relaciones históricas y de solidaridad entre Nicaragua y España. También conviene reflexionar sobre otro factor: el endurecimiento de las condiciones para entrar a los Estados Unidos. El muro de la frontera mexicano-estadounidense, la penalización del cruce ilegal, el aumento de las detenciones y deportaciones, el patrullaje fronterizo policial y paramilitar (Minute Men, Ranch Rescue y otros), y el terror de Los Zetas que secuestran, extorsionan y matan a los migrantes, han hecho que el sueño americano sea más costoso y riesgoso que el sueño español. En el supermercado mundial de la migración la relación calidad/precio también cuenta.

\subsection{Cuantificación}

Ya hemos dicho en la introducción que el Viceministro de Gobernación había anunciado que había en España más de dos mil mujeres somoteñas. Las diversas fuentes de los insumos de esta investigación difieren en cuanto a la cifra de migrantes de Somoto en San Sebastián.

Desde su sede en Madrid (España), la presidenta de la Asociación Solidaria Linda Nicaragua, Jamileth Toledo, contabiliza cada mes entre 10 y 25 migrantes procedentes de Madriz (Nicaragua) y de Nueva Segovia (Aguilera, 2010a).

Entre los más de 800 casos referidos por funcionarios de Migración y los más de 2,000 declarados por el Viceministro -recordemos que él no habla de San Sebastián sino de España en general-, la entrevista con Ivonne Guillén (EC1), responsable de una de las agencias de viaje, sugiere una cifra de 1,500 , teniendo en cuenta que sólo en su agencia se han vendido 460 boletos desde el año 2007 hasta marzo de 2009. Pero suponemos que la agencia no conoce el destino final de sus viajeros, pues ellos pueden vender boletos a París o Lisboa, o incluso a Madrid, sin saber exactamente cuántos de esos viajeros terminan en San Sebastián.

En la entrevista con Marcio Rivas (EC2), el ex alcalde sugiere una cifra de 1,200 mujeres en España, pero originarias de una región más amplia que Somoto, que incluiría San Lucas, Las Sabanas, Totogalpa e incluso Chinandega. Esta ambigüedad en la definición del municipio de salida existe también para los municipios y regiones de acogida, pues si bien el ex Alcalde se refiere a unas 600 mujeres que estaban empadronadas "hace dos años" (2007) en municipios de Guipúzcoa, también reconoce que hay otras en Madrid, Barcelona y Zaragoza (EC3). Y es que las redes humanas se van ampliando y el mismo fenómeno de la movilidad humana hace que no se pueda restringir a un espacio. 
Sin embargo, retengamos este último dato de 600 mujeres somoteñas empadronadas en Guipúzcoa en el año 2007, pues nos sirve para aclarar y objetivar todas estas declaraciones, y poder extrapolar la cifra al presente.

Si tenemos en cuenta que la ex Alcaldesa de Lasarte asegura que el 18\% de los inmigrantes nicaragüenses en el Estado español están en Guipúzcoa (Nagore, 2011b), y que el embajador nicaragüense en España daba hace pocos meses la cifra de 50 mil nicaragüenses presentes en ese país -aunque él mismo suponía una cifra real mayor (Aguilera, 2010b)-, tendríamos entonces una estimación cercana a los 9 mil nicaragüenses en Guipúzcoa. Observar la progresión oficial de nicaragüenses residentes en España nos puede ayudar a una estimación más objetiva.

\subsection{Expansión: 53\% más de nicaragüenses registrados en España en el último año}

El informe "Extranjeros residentes en España a 31 de diciembre de 2010" de la Secretaría de Estado de Inmigración y Emigración (2011a) ${ }^{2}$ señala que, en el último año, el número de nicaragüenses con certificado de registro o tarjeta de residencia en vigor en España ha aumentado de 3,740 (31 de marzo, 2010) a 4,072 (30 de junio, 2010), 4,415 (30 de septiembre, 2010) y 5,001 (31 de diciembre, 2010). Es decir, en tan sólo los últimos seis meses del año 2010 el aumento ha sido del 22,8\%. No hay fuentes para valorar la migración real, que incluye a los nicaragüenses en situación irregular, pero es de suponer que el crecimiento irá a la par.

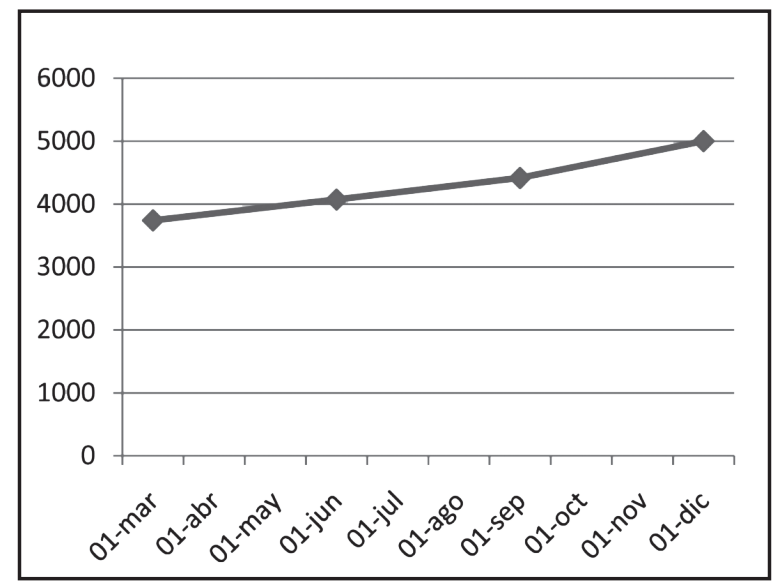

Ilustración 1. Nicaragüenses residentes en España

\footnotetext{
2 Se contabiliza a los extranjeros con certificado de registro o tarjeta de residencia en vigor. De todos los nicaragüenses (5001) residentes en España al 31 de diciembre de 2010, la mayoría pertenece al Régimen General (4034), es decir, el régimen jurídico que se aplica a los nacionales de terceros países, no incluidos en la Unión Europea. Sin embargo, hay un cierto número de residentes nicaragüenses que se acogen al Régimen Comunitario (967), el régimen jurídico de extranjería que se aplica a los nacionales de países de la Unión Europea y a los familiares de españoles que sean nacionales de terceros países.
} 
Si bien esa cifra oficial de 5,001 nicaragüenses residentes en España en el 2010 no es alta, si la comparamos con los 582 nicaragüenses que había en el 2005 (según la Encuesta de Medición de Nivel de Vida (EMNV) (Instituto Nacional de Información para el Desarrollo [INIDE], 2005), tenemos una progresión geométrica que en tan sólo cinco años casi multiplicó por diez la población nicaragüense en España.

De este crecimiento exponencial obtenemos un dato mucho más claro y contundente analizando los resultados del último de estos informes, correspondiente al 30 de junio de 2011 (Secretaría de Estado de Inmigración y Emigración, 2011b). Se contabilizan en esa fecha 5,133 nicaragüenses en el Régimen General, y 1,113 en el Régimen Comunitario, haciendo un total de 6,246 nicaragüenses registrados. Comparando con la misma fecha del año anterior (4,072 nicaragüenses registrados el 30 de junio de 2010), se evidencia un crecimiento del $53.3 \%$ en apenas un año. Es decir, si el crecimiento del segundo semestre de 2010 era del $22.8 \%$, el acumulado del último año (junio 2010 a junio 2011) es del 53.3\%. A nadie se le oculta que este resultado extraordinario es debido a la pura lógica de las relaciones humanas que mueven los hilos multiplicadores de la migración, algo en lo que merece la pena detenernos.

\subsection{Un mecate de henequén}

Este fenómeno expansivo puede ser explicado por diversas teorías migratorias, como las teorías neoclásicas macroeconómica (búsqueda de mejores salarios) y microeconómica (cálculo del costo-beneficio), la teoría de la nueva economía de la migración (estrategia familiar), las teorías del mercado laboral segmentado (demanda del Norte) y de los sistemas mundiales (de la periferia al centro), pero en cuanto a la progresión geométrica que acabamos de ver, la teoría de la perpetuación ofrece una explicación evidente: "Una vez que el número de migrantes alcanza un nivel crítico, las redes se expanden, los costos y riesgos se reducen y el número de migrantes se multiplica dando lugar a una espiral ascendente de más redes y de más migrantes” (Rocha, 2006, p. 28).

El efecto multiplicador de las redes hace que la migración se perpetúe. De hecho, la encuesta desvela que al irse a España las mujeres somoteñas ya tienen familiares (59\%), amigos (26.5\%) o conocidos (4\%). Las respuestas concuerdan con la pregunta concerniente a quién suministró la información para el viaje: familiares $(40.5 \%)$ y amigos $(35.5 \%)$. Los migrantes parecen atados a un mecate de henequén del que se produce en Somoto: unos van tirando de otros.

Junto a las redes, la teoría de la causación acumulativa explica otro de los elementos de la migración somoteña a España: el nicho laboral de trabajadoras domésticas es percibido socialmente como propio de las mujeres latinoamericanas, entre las cuales la mayor presencia es de ecuatorianas, bolivianas y colombianas. Aunque en España haya aumentado el desempleo a cifras superiores al 20\% de la población activa, el estigma hace que esos trabajos no se consideren apropiados para los oriundos.

Terminamos aquí este apartado en el que hemos visto el contexto y los antecedentes de la migración somoteña a España con referencia a algunas teorías 
migratorias. Entraremos más a fondo en la investigación separando el fenómeno en tres bloques: la preparación y el viaje, la situación de la mujer migrante en España y, por último, las consecuencias en Somoto, la comunidad de origen.

\section{Preparación y viaje}

\subsection{Motivaciones}

Tanto en las encuestas como en los grupos focales, las respuestas a las motivaciones son coherentes, ya sea que tomen el referente del ingreso ("por bajos salarios o falta de empleo") o bien el referente de las necesidades insatisfechas ("construir o mejorar la vivienda”, "estudio para los hijos”, “alimentación”). La metodología del estudio hace difícil objetivar una prioridad entre otras, pero en las respuestas destaca el tema de la vivienda sobre los otros.

\subsection{Estudios y ocupación en Nicaragua}

En cuanto a la ocupación que tenían antes de salir de Nicaragua, las encuestas confirman el dato dado en algunas entrevistas referente al elevado número de maestras que salen del país. Marcio Rivas, el ex alcalde, habla del grupo de profesoras de Totogalpa (EC2). A la pregunta por la ocupación, después de las que afirman haber trabajado como "ama de casa" (32\%) y de las que responden "no sabe" (16\%), aparecen en tercer lugar las "maestras" (9.5\%) seguidas de cerca por las "estudiantes" (8.5\%). Esta característica de una migración cualificada se confirma con las respuestas analizadas en el apartado del nivel escolar: $22.5 \%$ de los casos tienen estudios universitarios. Este dato concuerda con estudios a nivel nacional, como la EMNV (INIDE, 2005), en la que se reflejaba que entre la población de 25 a 29 años, 19\% de los migrantes tienen estudios universitarios, mientras que entre los no migrantes el porcentaje es de $15 \%$.

A la misma conclusión -una emigración con mayor nivel de estudio que la población en general-se puede llegar si tomamos en cuenta los estudios de secundaria: $50.5 \%$ de las encuestadas señalan haber terminado estudios de secundaria. A esa cifra hay que añadir el $22.5 \%$ de nivel universitario, pues también tienen estudios de secundaria, lógicamente. Eso nos da una cifra de 73\% de encuestadas que tienen nivel de secundaria. En la EMNV (INIDE, 2005), en el rango de población de 25 a 29 años, $45 \%$ de los migrantes tienen la secundaria, mientras que entre los no migrantes el porcentaje es $36 \%$. En la zona rural, para este mismo rango, la diferencia es aún más significativa: 39\% de los migrantes tienen estudios de secundaria, mientras que entre los no migrantes sólo el 17\% los tiene. Pero aún hay más. Si tomamos en cuenta sólo los migrantes a España, la EMNV-2005 señala que todas y todos los migrantes de 13 a 24 años llegaron hasta la secundaria y el 61\% de las y los migrantes de 25 a 29 años tienen estudios universitarios (INIDE, 2005). Es decir, el patrón migratorio a España expresa una migración con un nivel académico notable.

Sin embargo, viendo en nuestras encuestas la variable "Tenía empleo", se aprecia que la gran mayoría no tenía empleo antes de partir. Solo el 33.5\% de las 
encuestadas tenía empleo. Cruzando la variable "Tenía empleo" con "Nivel de escolaridad", vemos que a mayor nivel de escolaridad hay mayor porcentaje de casos con empleo: tenían empleo el 30.6\% de las que tenían estudios de primaria, $33.3 \%$ de las que tenían secundaria y $39.5 \%$ de las que tenían estudios universitarios. Se puede deducir que la migración no es tanto por la falta de empleo como por los bajos salarios, insuficientes para las necesidades básicas de una familia. Se confirma esta conclusión si cruzamos "Tenía empleo" con "Ocupación en Nicaragua”. Los mayores porcentajes de empleo se dan entre las ocupaciones que requieren mayor cualificación: técnica (57.1\%), promotora (50\%) y oficinista (42.8\%). Y sin embargo, emigran.

Estos datos que arrojan las encuestas de Somoto concuerdan con el perfil que el trabajo doméstico presenta a nivel mundial, cuando ese trabajo es realizado por migrantes: el nivel de cualificación es alto, en comparación con el nivel académico de las trabajadoras domésticas en países en desarrollo, como lo muestra el estudio de la Organización Internacional del Trabajo (OIT):

En gran parte del mundo en desarrollo estos trabajadores carecen por lo general de alfabetización básica puesto que muchos de ellos no han cursado una educación formal y han trabajado para familias desde la infancia. Por el contrario, los trabajadores domésticos migrantes de las economías más avanzadas pueden tener un nivel más alto de educación formal y cualificaciones profesionales, en particular como enfermeros o maestros (OIT, 2009, p. 11).

\subsection{Año en que migró}

Aunque la emigración de Somoto al País Vasco se inicia alrededor del año 2000, como ya hemos indicado anteriormente, se dispara a partir del año 2005, según las encuestas. Los primeros en irse no tuvieron ningún problema migratorio para llegar a su destino, y aquellos primeros casos llevaron después a España a sus hijos y familiares. Antes del año 2005 sólo habían emigrado 14 casos (7\%) de los estudiados. La progresión comienza bruscamente a aumentar en el año 2005 (10.2\%) y casi se duplica en el 2006 (19.8\%). Esa tendencia creciente no permite augurar un freno al fenómeno, pues la frecuencia más alta corresponde justamente al año anterior a la encuesta: sólo en el año 2009 salieron el 23.9\% de los casos estudiados.

\subsection{Costo del viaje}

En cuanto al costo de los preparativos y el viaje en sí, las encuestas señalan un costo evidentemente alto para el nivel medio de Nicaragua, pero más bajo que el costo de irse a Estados Unidos, pues en el rango entre 1,500 y 2,500 dólares se sitúan el $60.2 \%$ de las respuestas válidas. Se confirma el dato con la entrevista de la responsable de una agencia de viajes, que sitúa en alrededor de 2,000 dólares el costo del viaje, teniendo en cuenta el boleto, el seguro y el hotel (EC1). Es la misma cifra señalada por el ex Alcalde de Somoto (EC2).

Las deudas que se contraen para poder hacer frente a estos costos pueden convertirse en un círculo infernal si el proyecto migratorio no termina con éxito. Se 
piden préstamos a parientes o amigos, pero a unos intereses excesivos. También se piden a un banco, a una financiera o a la misma agencia de viajes, como afirma el alcalde actual de Somoto, Lic. Wilson Montoya, en el video-documental que formó parte del proyecto: "Tengo entendido que aquí ha habido una agencia que prestaba el pasaje y luego ellos lo estaban devolviendo". En cualquiera de los casos, para lograr el préstamo se suele dejar en prenda la casa o el solar. La migración, por lo tanto, ha potenciado la popularización de la usura debido a la falta de acceso a créditos en condiciones favorables.

Donde yo hice los préstamos fue una persona que me cobró al $8 \%$ pero hay otras que cobran $20 \%$. Esa señora se está haciendo rica a costilla del emigrante. Un pasaje les cobra más de 2,000 dólares. Ella les entrega el boleto. Pide 2,140 dólares más los intereses. Lo compramos en Managua y nos costó 1,370. Mucha gente tenemos que hipotecar las casas, para que mis hijos se fueran. Gracias a dios ellos son responsables y mandaron a pagar a tiempo (GF3).

\subsection{Ruta empleada}

Algunas agencias de viajes preparan a las mujeres con consejos sobre cómo vestirse, cómo peinarse y qué responder ante las preguntas que les harán en el aeropuerto de llegada (Aguilera, 2010a). El cambio de imagen y la estrategia de respuestas tienen como objetivo evitar la deportación en el mismo aeropuerto, donde las autoridades de migración consideran que aún no se ha entrado en territorio nacional.

Es difícil de valorar en las encuestas la variable de la ruta empleada, ya que hay un gran porcentaje $(75.5 \%)$ que no ha querido responder a esta cuestión. Sin embargo, entre las que han respondido (23\% del total), la casi totalidad ha llegado a España a través de Francia. Para los latinoamericanos hay mayor barrera en los aeropuertos españoles (Madrid y Barcelona) que en los del resto de Europa. Según la Agencia de Viajes consultada (EC1), los aeropuertos preferidos son París y Lisboa, vía México.

Junto con México, otro país intermedio usado como trampolín, está Venezuela. Las autoridades venezolanas han llegado incluso a Somoto para investigar las razones de este fenómeno, asegura el ex alcalde Marcio Rivas (EC2). También el Viceministro de Gobernación se refiere a la ruta venezolana y a la colaboración con autoridades de ese país (Sirias, 2008). Esta ruta seguiría, según el ex Alcalde, a París e Italia, llegando al País Vasco por tierra, a través de la frontera de Irún.

Hay que tener en cuenta que las rutas por países intermedios tampoco son siempre de tránsito inmediato. Esto ocurre especialmente en lo que se refiere a Costa Rica. Puede que la mujer somoteña que lleva tiempo en Costa Rica se decida a intentar una salida a Europa desde el aeropuerto de San José, uno de los aeropuertos centroamericanos con más destinos a Europa. Esta hipótesis puede ser sustentada con algunos datos de la investigación, pues en los grupos focales los adolescentes reconocen que sus familiares habían estado antes trabajando en Costa Rica o en Guatemala. 


\subsection{Hoy como ayer: ¿no somos de aquí?}

Todas esas rutas dibujan un mapa que refleja la multiplicación de la movilidad humana. Sin embargo, ese movimiento no es más que una prolongación de una dinámica histórica. Los primeros habitantes de Somoto eran chorotegas, la avanzadilla de las culturas mesoamericanas hacia el sur. Los historiadores señalan alrededor del año 595 la llegada de los chorotegas. Cuando siglos después llegaron los españoles, los habitantes de Nicaragua seguían considerándose un pueblo de migrantes. En la célebre entrevista entre el Padre mercedario Francisco de Bobadilla y trece caciques, en algún lugar próximo a la actual Granada, aquél les pregunta si eran naturales de aquella tierra y ellos respondieron: "No somos naturales de aquesta tierra, é há mucho tiempo que nuestros predeçessores vinieron á ella, é no se nos acuerda qué tanto há, porque no fue en nuestro tiempo" (Fernández de Oviedo, citado por Esgueva Gómez, 1996, pp. 25-26).

Tanto estos nicaraos como los chorotegas son pueblos que los primeros cronistas sitúan como originarios de la meseta de México. Huyeron de la servidumbre a la que estaban sometidos. En la entrevista de Francisco de Bobadilla éste pregunta a los caciques el motivo de su salida de México. Y ellos contestaron: “... viniéronse porque en aquella tierra tenían amos, á quien servían, é los tractaban mal”. Y el fraile insiste: ¿En qué los servían? ¿Por qué se vinieron? "En arar E sembrar E servir, como agora servimos á los christianos, é aquellos sus amos los tenian para esto é los comian, é por eso dexaron sus casas de miedo é vinieron á esta tierra de Nicaragua" (Fernández de Oviedo, citado por Esgueva Gómez, 1996, pp. 25-26).

Esta servidumbre les provocó una huida que es descrita por Juan de Torquemada en términos parecidos al éxodo de los israelitas ${ }^{3}$. Antes de entrar a Nicaragua, cual Moisés que muere sin llegar a la tierra prometida, el último de los caciques muere en tierras de Choluteca anunciándoles que llegará un tiempo en que "servirán a unos hombres blancos barbudos" a los que tendrán por señores, y que les tratarán incluso "peor que los Olmecas" (de Torquemada, citado por Esgueva Gómez, 1996, p. 27). La huida de la servidumbre no siempre ha conseguido evitar otras servidumbres.

Hoy, la presidenta de la Coordinadora de los Pueblos Indígenas Chorotegas, Daysi Pérez, anuncia un censo que cubrirá los departamentos de Madriz y Nueva Segovia, donde supone que viven todavía 85.000 de sus descendientes ("Indígenas chorotegas de Nicaragua censarán su población”, 2011). Sea como fuere, lo cierto es que la población de Somoto ha seguido migrando y miles de somoteños y somoteñas sueñan con esa tierra mientras en España cuidan niños, pasean ancianos o cocinan para un hogar. Ya no cocinan rosquillas y cosa de horno de su tierra, sino torta de papa y marmitaco vasco. Veamos entonces cuál es la situación de estas mujeres en España.

\footnotetext{
3 Otros cronistas, alegando siempre relatar las descripciones de los propios indígenas, sitúan ese éxodo en la costa, a través del mar. Es el caso de Fray Toribio de Motolinía en sus "Memoriales", que habla de una gran flota de barcas, y de Francisco de Gómara en su "Historia General de Indias" (Esgueva Gómez, 1996, pp. 32-33). En todo caso, sea por tierra o por mar, los habitantes de Nicaragua tenían conciencia de no ser naturales de esta tierra
} 


\section{Situación en España}

\subsection{Ocupación}

En cuanto a la ocupación que las migrantes tienen en España, las respuestas se concentran en tres labores: doméstica (41.5\%), cuidado de ancianos (34.5\%) y niñera (14\%). Estas tres ocupaciones aglutinan el 90\% de los trabajos de las mujeres de Somoto en España. Son contratos inestables y de duración variable: "En el caso de mi mamá, el contrato es hasta que se muera el viejito", afirma un participante de los grupos focales. La enfermedad de Alzheimer, con una alta prevalencia en España, provoca una fuerte demanda de personal para cuidar estos ancianos.

El trabajo doméstico es en efecto una de las ocupaciones más antiguas y más importantes para millones de mujeres del mundo entero, que hunde sus raíces en la historia mundial de la esclavitud, el colonialismo y otras formas de servidumbre. En sus manifestaciones contemporáneas, es un fenómeno mundial que perpetúa las jerarquías basadas en la raza, el origen étnico, la pertenencia a un grupo autóctono, la casta y la nacionalidad (OIT, 2009, p. 5).

Así se inicia el informe "Trabajo decente para los trabajadores domésticos” de la OIT (2009), en el que se señalan como problemas característicos de este sector: la informalidad y la falta de reconocimiento de problemas de seguridad y salud en el trabajo, la falta de licencias de maternidad y la consecuente facilitación de abortos, la facilidad del acoso y el abuso en los casos en que ellas trabajan internas, el peligro del trabajo forzado, los obstáculos a la organización sindical, etc.

Este informe de la OIT describe el trabajo doméstico de los migrantes como "una cadena de servicios domésticos mundiales" en la que el Norte recibe los servicios y el Sur está condenado a ofrecerlos a costa de la separación familiar.

La migración femenina de mujeres para hacerse cargo del servicio doméstico en el extranjero crea hogares «transnacionales», o sea una forma de cadena de servicios domésticos mundiales entre, por una parte, trabajadores del Norte y con responsabilidades familiares necesitados de servicios de apoyo para la familia y, por otra parte, migrantes temporales del Sur que puedan prestar esos servicios, aunque sea a expensas de sus propias familias que abandonan (OIT, 2009, pp. 10-11).

Aunque esta investigación se centra en las mujeres, Marcio Rivas (EC2) señala el trabajo rural de algunos hombres nicaragüenses en España, que podría considerarse también doméstico, pues se trata de un trabajo relacionado con la explotación ganadera familiar, llamada "caseríos" en el País Vasco. Su testimonio coincide con el de un participante de los grupos focales: "son los que ordeñan, los levantan oscuro a ordeñar, me supongo que ha de ser pesado". Sin embargo, el grueso de la migración nicaragüense a España son mujeres. 


\subsection{Feminización}

Del informe, "Extranjeros residentes en España a 30 de junio de 2011" de la Secretaría de Estado de Inmigración y Emigración (2011c), se destaca una feminización de la migración nicaragüense a España. Veamos en primer lugar la proporción por sexos entre la población extranjera residente en España: en el Régimen General son mujeres el $46.24 \%$ y en el Régimen Comunitario son mujeres el $48.31 \%$. Esta proporción, más o menos equilibrada en relación a cualquier población -más bien ligeramente baja la representación de la mujer-se vuelve asombrosamente asimétrica si nos fijamos solamente en los inmigrantes nicaragüenses en España, pues el porcentaje mayor es abrumadoramente femenino. De entre los 6,246 nicaragüenses registrados o con autorización de residencia en España, a 30 de junio de 2011, 1,654 son hombres (26.5\%) y 4,592 son mujeres (73.5\%). Seis años antes ya existía un porcentaje semejante, pues en la EMNV (INIDE, 2005), del total de migrantes nicaragüenses en España, los hombres eran el 19.2\% y las mujeres el $80.8 \%$.

Cuadro 2. Progresión de la migración nicaragüense a España 2005-2011 (Sólo residentes)

\begin{tabular}{|c|c|c|c|c|}
\hline & \multirow[t]{2}{*}{$\begin{array}{l}\text { EMNV } \\
\text { (Nicaragua) } \\
2005\end{array}$} & \multicolumn{3}{|c|}{$\begin{array}{l}\text { Observatorio Permanente de la Inmigración } \\
\text { (España) } \\
30 \text { de junio de } 2011\end{array}$} \\
\hline & & Total & $\begin{array}{c}\text { Régimen } \\
\text { general }\end{array}$ & $\begin{array}{c}\text { Régimen } \\
\text { comunitario }\end{array}$ \\
\hline Hombres & $112 \quad(19.2 \%)$ & $1654(26.5 \%)$ & 1339 & 315 \\
\hline Mujeres & $(80.8 \%)$ & $4592 \quad(73.5 \%)$ & 3794 & 798 \\
\hline TOTAL & 582 & 6246 & 5133 & 1113 \\
\hline
\end{tabular}

Fuente: INIDE (2005) y Secretaría de Estado de Inmigración y Emigración (2011b).

Se puede concluir que la feminización de la migración de Somoto a San Sebastián (Guipúzcoa), tan llamativa en nuestro estudio, sigue un patrón parecido a la migración nicaragüense a España. Y esta feminización se da también, como veremos más adelante, a la hora de elegir la persona que recibe las remesas.

\subsection{Salario}

Si nos atenemos puramente a las respuestas, la conclusión sería que el trabajo de las mujeres nicaragüenses no está tan mal pagado en España: sólo el 12.6\% de las encuestadas cobraría 600 euros o menos, por debajo del Salario Mínimo Interprofesional (SMI), situado en el 2010 en 633.30 euros mensuales (21.11 euros al día $)^{4}$. Sin embargo, aunque la gran mayoría gane más del salario mínimo, las

\footnotetext{
4 En comparación con el resto de países europeos, el SMI español es de los más bajos. Según la Oficina Estadística Comunitaria (Eurostat), mientras en el año 2008 el SMI de España estaba en $600 €$, en otros países de Europa estaba establecido en 1,610€ (Luxemburgo), 1,462€ (Irlanda), 1,357€ (Holanda), 1,336€ (Bélgica), 1,321€ (Francia) o 1,148€ (Gran Bretaña). Sólo Portugal, Polonia, Rumanía y Bulgaria tenían un SMI inferior al español ("Salario Mínimo Interprofesional", 2010).
} 
somoteñas saben que "la vida no es moronga", como dice un refrán nicaragüense. Teniendo en cuenta que las ocupaciones principales señaladas en el punto anterior van asociadas a muchas horas extraordinarias que no suelen ser pagadas como tales, nos atrevemos a sugerir otras interpretaciones no tan satisfactorias con respecto al salario. En primer lugar, el grueso de las respuestas $(53.4 \%)$ se concentran en un salario que roza el mínimo: entre 700 y 800 euros mensuales. Si usamos el criterio popular de pobreza en España, donde se identifica a los pobres como aquellos que ganan mil euros o menos -llamados por eso "mileuristas"- nos encontramos con el $86.3 \%$ de los casos encuestados, lo cual coincide con la información dada por el ex alcalde, Marcio Rivas, que señala la cantidad de 800 a 1,200 euros al mes como la más normal en cuanto a los ingresos que logran las mujeres somoteñas en España (EC2).

Pero aún podemos profundizar más, ya que existe un Salario Mínimo Interprofesional para los empleados del hogar (Foro-Industrial.com, 2011), establecido en el año 2010 en 4.96 euros por hora trabajada. La mayoría de mujeres que trabajan internas en un hogar tienen horarios que significan la permanencia continua al lado de la persona que cuidan. Es el caso de Rafaela Espinosa, nombre ficticio de una mujer que en un artículo en El Nuevo Diario (25 de julio de 2010) cuenta cómo dispone solamente de 12 horas libres a la semana cuidando a un anciano en un pueblo del País Vasco y ganando 1,200 euros al mes (Aguilera, 2010a). Eso es mucho menos de los 4.96 euros por hora trabajada que exige el Salario Mínimo Interprofesional para los empleados del hogar, incluso si no se consideraran las horas de sueño nocturno, suponiendo que la anciana que ella cuida no dé problemas durante esas horas, lo cual es poco probable. 
Cuadro 3. Régimen Especial de Trabajadores del Hogar (en España)

Al menos hasta el año 2010 estaba en vigor el Régimen Especial de Trabajadores
del Hogar, al margen del Estatuto de los Trabajadores y del Trabajo Autónomo. A
este Régimen Especial, en vigor desde 1985 (Real decreto 1424/1985) y con escasos
derechos laborales, pertenecían 300 mil personas, de las que más del 90\% eran
mujeres y alrededor del $60 \%$ inmigrantes. Sin embargo, el hecho de ser un sector
tradicional de economía sumergida, sitúa las estimaciones reales de trabajadoras
domésticas en el doble del número de afiliadas.
El Régimen Especial de Trabajadores del Hogar no obliga al empleador
a hacer un contrato por escrito, lo cual no permite a la trabajadora del hogar
demostrar las condiciones que habían sido fijadas. Las indemnizaciones por
despido son menores que en el régimen general. No hay derechos por accidente de
trabajo ni derecho a la prestación por desempleo. El punto más problemático es el
pago en especie, pues los empleadores valoran de manera aleatoria el alojamiento y
la manutención dadas a las trabajadoras internas, y según la ley ese pago en especie
puede llegar a suponer el $45 \%$ del salario.
En el año 2010 se iniciaron negociaciones entre el gobierno y los sindicatos
para eliminar este régimen especial y así integrar a las trabajadoras domésticas en
el régimen general, con los mismos derechos que los demás trabajadores, pero las
negociaciones están estancadas.
(Ver más información en Anexo 1)
Fuente: Requena Aguilar (2010)

\subsection{Cadenas transnacionales de cuidado}

Analistas en género y migración concluyen que la incorporación de la mujer al mercado laboral no ha provocado un reparto de tareas con el hombre, ni una regulación de los horarios para compatibilizarlos con la vida familiar, sino que se ha recurrido a otras mujeres, migrantes, que forman las "cadenas de cuidado transnacionales" llamadas "la mundialización del amor materno" por algunos autores como la profesora de sociología de la Universidad de California, Arlie Russell Hochschild:

Las mujeres del Sur son las nuevas criadas del Norte. Cuando emigran, dejando maridos y niños, generalmente es para ocuparse de los niños de las familias de los países ricos. Con ellas aparece una nueva transferencia de género entre el Sur y el Norte: una transferencia de cuidados y de atención..., una transferencia de amor (SJM-España, 2010, p.22).

El trabajo doméstico se transforma en un trabajo de "cuidados" de menores de edad, mayores y dependientes, por lo que, además de cocinar, lavar y planchar, hay que acompañar, cuidar y querer. La mayor autonomía de la mujer obliga a buscar quién cuide de los que carecen de autonomía. Y el recurso más fácil es buscar otras mujeres que lo hagan, construyendo así una "cadena global de cuidados", como se advierte en este documento que SJM-España ha elaborado recientemente: 
Todo ello supone la sustitución del "trabajo" no remunerado hecho tradicionalmente por las madres, hijas, abuelas, sobrinas... por un trabajo "mal" remunerado. Es un proceso claro de interrelación entre relaciones de género y proceso migratorio. La "cadena global de cuidados" e internacionalización de la intimidad reclama trabajadoras de los países del Sur para la atención de las necesidades de cariño de las familias del Norte: icómo se vive la experiencia de criar a los hijos de otras madres, sin ver crecer a los tuyos? ¿Cómo se soportará ver morir a la anciana madre de tu empleador sin haber podido despedir a tu propia madre? Y por el lado de las familias empleadoras, icómo se vive que el cariño a los nuestros sea ofrecido por otras personas (mujeres)? (SJM-España, 2010, p. 22).

Estas mujeres ya han comenzado a asociarse. En el País Vasco hay experiencias interesantes de dignificación del trabajo doméstico a través de cooperativas, como la Cooperativa Servicios Sociales Integrados (SSI) de Bilbao, surgida en los años 80, y gestionada íntegramente por mujeres, con un convenio laboral propio. Otro ejemplo es la Cooperativa "Euskarri-Un paso más" para quienes trabajan en el acompañamiento a personas (SJM-España, 2010, p. 14). Ofrece un plan de trabajo a medio tiempo durante tres años de formación: ayuda a domicilio, geriatría, menaje y tareas del hogar, cuidados de personas con demencias, técnicas de movilización, estrategias de auto cuidado, etc. Se incluye una formación humana que incide en la valoración del ser mujer y la dignificación de la persona. Además de la formación, las cooperativas garantizan la responsabilidad en el servicio, evitan los abusos en los contratos y ayudan a visibilizar el sector. Sin embargo, en ninguno de los insumos de la investigación aparecen indicios de que las somoteñas conozcan y participen de esas cooperativas.

\subsection{Relaciones sociales en España}

Ya nos habíamos referido anteriormente a las redes que son causa de la migración y a la vez consecuencia. Al irse a España, el 59\% ya tenía familiares allí, el 26,5\% tenía amigos y el $4 \%$ conocidos, según las encuestas.

En otra de las preguntas, referente a si tienen pareja en España, un 19.4\% afirman tenerla. Hay que tener en cuenta que, en otro de los apartados, el 28.5\% afirman tener esposo en Nicaragua, el $15.5 \%$ un compañero y $0.5 \%$ el novio. Cruzando las variables "pareja en España" con "pareja en Nicaragua", aparecen curiosamente algunos casos en los que responden tener pareja en España y al mismo tiempo tener en Nicaragua esposo (tres casos) o compañero (un caso). Es evidente que este tipo de procesos pueden ser más frecuentes, ya que son temas difíciles de tratar en una encuesta, pero es una realidad que no puede quedar al margen de las investigaciones sobre migración. De hecho, el tema de las rupturas conyugales aparece también en buena parte de los grupos focales y en las entrevistas.

Aparte de las redes interpersonales y comunitarias en las que participan, no hay en las encuestas información sobre asociacionismo entre las migrantes nicaragüenses en España. Por otros medios sabemos que existen esas asociaciones, como la ya citada Asociación Solidaria Linda Nicaragua, presidida por Jamileth Toledo. Para algunos analistas, el asociacionismo entre migrantes se dificultaría 
porque ven ya satisfechas sus necesidades de asistencia y ayuda a través de las redes informales de parentesco, compadrazgo, paisanaje y amistad, como lo muestra el estudio "Las asociaciones de inmigrantes en España. Una visión de conjunto":

De modo que la mayoría de los que emigran, fuera de los iniciadores y pioneros de una particular corriente migratoria, lo harían hoy guiados y ayudados por familiares o amigos o conocidos con los que, antes de formar verdaderas asociaciones, están de alguna manera vinculados en su país de origen o en el de su destino o en ambos y esto les aportaría casi todo lo que de las asociaciones formales podrían esperar e incluso la manera de interpretar lo que les liga con éstas cuando en ellas participan” (Aparicio Gómez \& Tornos Cubillo, 2010, p. 27).

Para la primera prioridad de un migrante, la búsqueda de trabajo, ese estudio demuestra que entre la comunidad ecuatoriana en España, por ejemplo, el logro del puesto de trabajo se debe en un 76,1\% a parientes y amigos, un $12 \%$ a "recorrer sitios", un $4.3 \%$ a la agencia de trabajo, otro $4.3 \%$ a la búsqueda en la prensa y en porcentajes del $1.1 \%$ a ONG, el INEM y "otras cosas". La casilla correspondiente a "asociaciones de inmigrantes del propio país" marca 0\%. Curiosamente, entre los marroquíes o los chinos, estas asociaciones sí logran algún porcentaje de éxito, aunque siempre insignificante (1.1\%) (Aparicio Gómez \& Tornos Cubillo, 2010, p. 28).

Sin embargo, de cara a la participación ciudadana y a la acción política, no es posible la incidencia si no se da el paso a la creación de entidades formales. Para ello sería deseable que las alianzas y solidaridades en los países de acogida ayudasen a esas asociaciones a ser cauce para el logro de puestos de trabajo, con el objetivo de crear confianza y fortalecer un instrumento de cambio social indispensable.

\subsection{Impacto socio-emocional}

Los nicaragüenses llaman "cabanga" a la nostalgia, tal como la canta Carlos Mejía Godoy: "Cuando lejos te tengo patria mía, la cabanga me muerde el corazón. Me hacen falta tus lagos y tus ríos, los encendidos ojos de tu sol" (Yo te amo, Nicaragua). Comenzamos por señalar ese sentimiento porque esa nostalgia enmarca el resto de problemas que las somoteñas viven en España.

Entre los riesgos y temores que aparecen en la investigación, los accidentes y enfermedades ocupan un lugar importante. Esta es una de las respuestas a la pregunta sobre los peligros: "Hay muchos. Les han pasado accidentes en el trabajo, en la calle, algunas que no van a lo que van, accidentes, porque en Ocotal trajeron una muchacha que murió en un accidente".

Las enfermedades se asocian a la diferencia del clima. El País Vasco es una región fría y buena parte del año hay calefacción en las casas, lo que ocasiona, al salir a la calle, cambios bruscos de temperatura que son causa de temor entre los migrantes nicaragüenses, provenientes de un clima cálido. Así lo expresa un testimonio recogido en los grupos focales: 
Lo más peligroso allá es agarrar una tuberculosis porque cuando está allá lloviendo y uno está trabajando en lo caliente y después salir de lo caliente en la noche se siente que los huesos se están quebrando. Se enferman por el clima, les da asma, dolor en los huesos y en esos días no pueden trabajar.

En los casos de muerte por accidente, la comunidad nicaragüense migrante se moviliza para la repatriación del cadáver. Así fue en el caso de Audia Isabel, de Ocotal, que fue atropellada en San Sebastián la víspera de su primer trabajo, el 22 de febrero de 2009. Entre las nicaragüenses radicadas en el País Vasco, y la ayuda de la Iglesia, lograron juntar los 4 mil euros necesarios para la repatriación. Su muerte coincidió con la creación de la Asociación Solidaria Linda Nicaragua ("Dramática suerte de inmigrante", 2009).

Según el testimonio de una ex emigrante que estuvo en España, su experiencia fue negativa por varias razones: la separación de sus hijos, la deuda que dejó, la falta de suficiente dinero para asegurarse hospedaje y alimento durante el viaje y en las primeras semanas, la situación de indigencia en la que estuvo durante un mes de invierno en el que no trabajó y se expuso a las inclemencias del frío, el maltrato en los empleos y la dificultad para realizar trabajos en los que no tenía experiencia. Otros viven con el temor a la deportación, a la prisión o a los centros de internamiento que en los últimos años han proliferado en España. El racismo y la discriminación se objetiva en las redadas y en las detenciones que se denuncian desde organizaciones como Caritas, que documenta un control de los migrantes incluso a la puerta de sus centros.

También entrarían en este apartado los temores a los trastornos psico-afectivos como la depresión, el alcoholismo y la drogadicción. Con todo, creemos que los problemas más graves y específicos estarían ligados a la discriminación y violencia de género, dada la feminización que caracteriza esta migración somoteña al País Vasco. Y en relación con ello, el caer en las redes de la "trata" de personas es un riesgo que merece un tratamiento en profundidad.

\subsection{Trata y prostitución}

Aunque son dos temáticas distintas, las tratamos a un tiempo con el objeto, precisamente, de diferenciar las particularidades de cada una. Hay modalidades de trata con fines diferentes a la explotación sexual. Para comenzar, hay que señalar que no aparecen, en las diferentes herramientas metodológicas usadas, muchas referencias que objetiven condiciones de trata de personas para la prostitución. "No se conoce de personas o redes que estén promoviendo viajes con intenciones sospechosas", se señala en uno de los grupos focales (GF1). En ese mismo grupo se afirma conocer "rumores de prostitución pero como actitudes particulares no generalizadas". Y en las entrevistas claves encontramos la misma reacción.

Sin embargo, aunque es un problema que cuesta hacer emerger debido a la vergüenza asociada a la prostitución y a la clandestinidad de las redes, aparecen siempre signos que son la punta del iceberg. En un grupo focal aparece una migrante retornada de España cuya experiencia fue muy negativa. Ella pasó un mes sin empleo y sin hospedaje seguro, en la época más fría del invierno, y relata haber sufrido malos 
tratos en su trabajo. Su testimonio es importante porque asegura haber conocido somoteñas practicando la prostitución: "Pude comprobar que muchas emigrantes de todos los países dicen a sus familiares que trabajan en una cosa y hacen otra. Trabajé en una casa de citas en limpieza. Habían de Costa Rica e incluso de Somoto” (GF3).

En la transcripción de otro grupo focal, una participante retornada dice:

Cuando yo me fui a trabajar estaba mi cuñada allá. Ella decía que estaba cuidando un anciano. La curiosidad... me fui porque aquí en Somoto no trabajo. Dejé a mis hijos con mi esposo y ella me tenía el trabajo allá. El susto mío es que ella no estaba cuidando un anciano, estaba 'haciendo otro trabajo'. Claro, yo sí me busqué un trabajo para cuidar ancianos. Pero ella no (GF1).

"Andan en otra cosa" es una expresión utilizada para referirse a la prostitución. En otra intervención se afirma:

Andan tal vez en cosas que no deben. Les pueden pasar cosas en la calle. Uno sabe que se van a trabajar pero ya puestas allá piensan en otra cosa. Se dice que van a una cosa y andan en otra (GF1).

Pero el problema de la trata de personas es más amplio que el de las redes de prostitución. Puede que la mujer esté trabajando en el servicio doméstico, o incluso que tenga su permiso de trabajo y su residencia, pero si ha sido llevada con engaños, si los empleadores la han seleccionado a través de una red que le quita su pasaporte y sus papeles, entonces estamos hablando del delito de "trata" de personas. Y esto es lo que denunciaba el viceministro de Gobernación en el año 2008 en el artículo citado de El Nuevo Diario:

Mucha gente sale del país engañada, en Somoto hay casi dos mil mujeres que han emigrado a España, si bien es cierto se les ofrece un sinnúmero de bondades, cuando llegan al destino les quitan el pasaporte y les deducen de sus salarios, por seis meses, el pago del boleto aéreo, cuando nada de eso estaba en el contrato antes de viajar (Sirias, 2008).

El dato más objetivo que se tiene es una noticia reciente del diario La Prensa. El 30 de octubre titula: “Cae banda que prostituía en España a mujeres nicas”. Los hechos ocurrían en la ciudad de Gandía y por ello fueron detenidos un hombre chino y dos mujeres nicaragüenses (“Cae banda que prostituía...”, 2011).

La situación amerita una investigación focalizada en este problema. En los insumos aparecen indicios de prostitución, pero los testimonios parecen referirse a una prostitución "voluntaria”, si es que puede llamarse así cuando la situación de las mujeres migrantes llega a ese punto, después de haber visto violados sus derechos. La protección de las víctimas y su compensación deberán priorizarse antes que su estigmatización. 
Cuadro 4. Definición de trata según Protocolo de Palermo

Protocolo para prevenir, suprimir, castigar la trata de personas, especialmente mujeres y niños, que complementa la Convención de las Naciones Unidas en contra de la Delincuencia Organizada Transnacional, octubre de 2000.

Según el artículo 3) inciso a) de este protocolo se define la trata de personas como:

"la captación, el transporte, el traslado, la acogida o la recepción de personas, recurriendo a la amenaza o al uso de la fuerza u otras formas de coacción, al rapto, al fraude, al engaño, al abuso de poder o de una situación de vulnerabilidad o a la concesión o recepción de pagos o beneficios para obtener el consentimiento de una persona que tenga autoridad sobre otra, con fines de explotación. Esa explotación incluirá, como mínimo, la explotación de la prostitución ajena u otras formas de explotación sexual, los trabajos o servicios forzados, la esclavitud o las prácticas análogas a la esclavitud, la servidumbre o la extracción de órganos”.

Este protocolo entró en vigencia el 25 de diciembre de 2003. En Nicaragua, el delito de trata está tipificado en el numeral 182 del Nuevo Código Penal.

En todo caso, habrá que diferenciar la "trata de personas" del "tráfico ilícito de personas", pues en éste, el tráfico termina cuando la persona migrante llega a su destino, y el delito sería, en todo caso, contra la soberanía del Estado y no contra la persona que ha pagado al traficante por ayudarle a cruzar la frontera (Sánchez Paz, 2008, p. 18).

\subsection{Tiempo en España}

Aunque hay algunas mujeres que ya han regresado -como es el caso de algunas que dan su testimonio en el video-documental- otras siguen allá, ante la perspectiva de un país estancado en su desarrollo. Es difícil cuantificar el tiempo, pues depende de si han dejado esposo e hijos, o de si los pueden llevar después de su regularización en España, o de si huyen de una estigmatización en su comunidad por ser madres solteras. En uno de los testimonios, el criterio del esposo es, sencillamente, pagar la deuda:

En el momento que termine de pagar la deuda, si ella se quiere venir que se venga, hemos sido pobres y me conformo con lo que Dios me ha dado. Para mí lo más importante es la unión familiar, somos casados y yo no quisiera perderla porque los hijos, es bonito que se críen con su mama, con su papa, pero en la vida siempre hay tropiezos, puedo fallar yo como hombre, puede fallar ella como hembra y yo le digo a ella, si termina de pagar la deuda véngase de una vez porque lo importante es que la familia esté unida (GF1). 


\section{Consecuencias en la comunidad de origen}

\subsection{Remesas: parentesco del que las recibe}

Las encuestas revelan que las remesas son recibidas en primer lugar por las madres $(31.3 \%)$ y por los esposos (26.8\%), seguido de las hijas $(8 \%)$ y el padre $(8 \%)$, luego las hermanas $(7 \%)$ y la abuela $(4,4 \%)$, y en casos infrecuentes, por otros parientes (hijo, esposa, prima). Pero en la lista de parentescos que salen en las respuestas llama la atención, si los separamos por sexo, que los agrupados en sexo femenino reciben más remesas que los varones: $19 \%$ frente a $14.5 \%$. Es significativo, por ejemplo, que por cada 21 casos que envían remesas a la madre, sólo 6 envían al padre. El envío es hecho a la hermana en cinco casos, mientras que sólo tres casos consignan a un hermano. Por cada seis remesas giradas a las hijas, hay sólo dos remitidas a los hijos. Aparecen incluso casos de remesas enviadas a la abuela o a una prima, pero ningún caso de envíos a un abuelo o a un primo. La única excepción es la frecuencia de remesas a los esposos (9\%), pero hay que tener en cuenta que el estudio se está realizando a mujeres. Fuera de esa relación esposa-esposo, en todas las demás relaciones familiares destaca el sexo femenino en la recepción de remesas. Un reciente estudio de OIM-UNICEF en Guatemala confirma la misma tendencia: los receptores de remesas son el 65.5\% mujeres y el 34.5\% hombres (OIM \& UNICEFGuatemala, 2011, p. 20).

\subsection{Cantidad enviada}

El ex alcalde Marcio Rivas (EC2) señalaba la cantidad de 400 euros al mes como la más frecuentemente enviada por las mujeres somoteñas en España. Otros testimonios dan cifras parecidas. Entrar en baremos y rangos estadísticos a partir de las encuestas, realizadas en el año 2009, nos alejaría de una visión más actualizada que ha de tener en cuenta los dos últimos años de crisis económica que, en España, han afectado especialmente a los migrantes. En los últimos dos años las remesas enviadas desde España han sufrido una variación considerable: una caída significativa desde que comenzó la crisis económica y un freno a esa caída en el año 2010. El 30 de marzo de este mismo año el Banco de España ha dado a conocer que, tras dos años de caídas en las remesas de los inmigrantes que trabajan en España, en el último año se han logrado mantener en 7,186 millones de euros. El año 2008 se había cerrado con una caída de las remesas del 7,1\% y en el 2009 el descenso había sido aún más duro, el 9,7\%. En este último informe, del año 2010, apenas hay un $0.3 \%$ de descenso, según la noticia recogida por la agencia Europa Press ("Las remesas de los inmigrantes se mantienen...", 2011). La crisis se ha cebado en los migrantes, los primeros en ser afectados por los despidos, pero la noticia reciente del Banco de España hace presagiar que la recuperación ya ha iniciado.

\subsection{En qué se invierten}

Prioritariamente, después del pago de la deuda, las remesas se invierten en la construcción de casas (EC1, EC2). No aparece en el estudio ningún indicio de una 
inversión directamente comunitaria de las remesas. Éstas tienen, sin duda, impactos comunitarios y sociales más allá del ámbito familiar, pero en la investigación no se vislumbra ninguna utilización directamente social, como podría ser ahorro para la creación de pequeña o mediana empresa o de una cooperativa. Una de las críticas al potente fenómeno migratorio actual es que ha despolitizado la lucha por el desarrollo social. No se aprecian remesas "políticas" o "sindicales". Las mejoras en salud, en vivienda o en educación, no se demandan al Estado, sino que se suponen responsabilidad exclusiva del individuo. De todos modos eso no impide el que se reconozca a los migrantes la mejora de la alimentación, la vivienda y la educación de una comunidad gracias a las inversiones realizadas con las remesas.

\subsection{Impacto socio-emocional en la comunidad de origen}

La "desintegración familiar" (EC3) o el "abandono de cónyuge e hijos" (EC1), es el problema más citado. En la vida conyugal y afectiva, la dificultad de la separación es vista como un obstáculo casi insuperable, especialmente por los esposos. Un participante de los grupos focales afirma:

Después que tienen tres meses, yo le pido todos los días al Señor. Para nosotros los hombres es completamente difícil, es complicado completamente dejar de tener relaciones, pero yo creo que hay un Dios que todo lo puede, todos los días le pido, "Señor, no me dejes tropezar". Quiero que ella sea feliz. A mí me hace mucha falta, demasiada falta.

En el grupo focal con adolescentes (GF2) estos hijos de inmigrantes señalan tener entre dos a cinco parientes radicados en el extranjero. Las consecuencias de la migración en la transformación de la familia tradicional somoteña es un tema que merecería estudios ulteriores y que esta investigación exploratoria sólo esbozará. Se vería lógico que la manera de afectar la migración a la familia fuera diferente según el modelo de familia previo. La partida de la madre tendrá consecuencias diferentes en un hogar en el que el jefe de familia era el hombre, que en aquellos hogares -generalmente monoparentales- en los que el jefe de familia era la propia mujer que se fue. De igual manera, habría que considerar de modo particular las familias ampliadas y extensas, en las que son muchos los miembros que dependen del ingreso de la mujer migrante. Esto hace que la carga psicológica que implica esta responsabilidad incida en una mayor aceptación de condiciones a veces indignas por parte de las mujeres migrantes, favoreciendo las violaciones de sus derechos.

La recomposición familiar que la migración provoca es de difícil percepción, incluso para los propios miembros de la familia. En el grupo focal con adolescentes (GF2) se afirma ingenuamente no conocer problemas familiares a causa de la separación, más allá del duelo por la ausencia de la madre y las conductas negativas entre los adolescentes. Pero luego, algunas conductas que ellos señalan, como el abandono de los estudios, la depresión, el suicidio, la violencia, las adicciones y la integración a pandillas, son identificadas como consecuencias de la migración. De igual manera, la adopción de roles nuevos en el hogar no parece plantear problemas. Varios testimonios hacen ver que el hombre que queda a cargo de los hijos comienza 
a encargarse de hacer la comida: "Pasan tantas cosas que se aflige uno cuando se va su madre, pero siempre los tiempos pasan, las razones, hacer la comida, pero mi padre nos hace la comida puntual" (GF4).

La anomia o falta de disciplina de los niños y jóvenes que crecen sin una autoridad, es el inconveniente señalado por el ex alcalde Marcio Rivas (EC2) y por Randolf Acuña, delegado departamental del Ministerio de Gobernación (EC3).

Con todo, todas estas consecuencias en la salud física y emocional de los hijos que sufren el duelo por la "migración parental" tienden a minusvalorarse frente al cambio económico que suponen las remesas. En una de las conclusiones de ese mismo grupo focal se afirma: "Todos manifiestan haber sentido dolor por la ausencia de sus madres o hermanos al principio, pero actualmente expresan conformidad y comprensión de la necesidad de la separación por razones económicas" (GF4).

En el testimonio de un adulto, el hecho de minusvalorar el duelo hace también desestimar las consecuencias psicosociales en los hijos: "A veces están tristes, se ponen a llorar. No tienen cambios notables que preocupen”. La angustia y el abatimiento provocados por la tristeza de la separación, no son cosas que "preocupen".

En otros estudios se ha visto que los cambios que la migración parental provoca comienzan a veces por la mudanza incluso física a la casa de los abuelos, con todo lo que este cambio espacial significa para el imaginario de los niños. El Informe de la OIT, "Trabajo decente para los trabajadores domésticos”, llama la atención sobre este problema de las familias "transnacionales" de las mujeres que hacen trabajo doméstico:

Sea como fuere, las prácticas de migración restrictivas pueden redundar en una separación prolongada y una carencia de cuidado de los niños de esas familias transnacionales, que deberán confiarse al cuidado de miembros del núcleo familiar más amplio o de empleados domésticos locales mal remunerados (OIT, 2009, pp. 10-11).

A veces incluso los niños se quedan solos y es la hermana mayor la que pasa a desempeñar la labor de cabeza de familia. Aunque no ha aparecido ese caso entre los grupos y personas seleccionados, sin duda que existen menores de edad que son cabeza de familia en Somoto, ya que es una realidad cada vez más frecuente y que ha sido abordada recientemente en un estudio de la OIM y UNICEF en Guatemala, que confirma que hay 640 menores de edad de sexo femenino, con edades comprendidas entre los 10 y los 14 años, que a causa de la migración son cabezas de familia y responsables de sus hermanos menores (OIM \& UNICEF-Guatemala, 2011).

Entre otros elementos a considerar -que en esta investigación no se han abordado, por ser exploratoria- estaría, además de la dimensión de salud física y emocional, la dimensión educativa. En algunos estudios sobre las consecuencias educativas en hijos de migrantes se comprueba que el rendimiento escolar de los niños varones disminuye, mientras que el de las niñas aumenta (Fe y Alegría - Bolivia, 2010, pp. 27 y 43). Habría que ver si cuando es la mamá la que emigra, como es el caso en Somoto, las niñas presentan este patrón o si tal vez un supuesto aumento de sus tareas en el hogar dificulta su dedicación al estudio. Otros factores, como el mayor acceso a una computadora y al Internet, o la perspectiva de una posibilidad de 
seguir estudios universitarios, pueden lógicamente incidir en un mejor desempeño escolar en los hijos de migrantes. Sin embargo, esa disponibilidad de recursos podría incidir también negativamente, ya que esos niños y niñas tienen al mismo tiempo acceso a nuevas formas de usar el tiempo libre, como bicicletas o motos, aparatos de sonido, juegos de ordenador y otras diversiones sobre las que las abuelas no pueden orientar hacia un uso controlado y útil.

No obstante todos estos elementos del ámbito escolar, hay que recordar que la educación no se reduce a la escuela, y habría que valorar todo el campo del comportamiento que ha sido señalado anteriormente, tanto en los grupos focales como en las entrevistas claves. Es una percepción general que los hijos de migrantes tienen mayor facilidad de caer en conductas disfuncionales e incluso delictivas. Esa es al menos la respuesta en la mayoría de insumos, si exceptuamos uno de los grupos focales realizado con parientes adultos de migrantes, en el que no relacionan de forma directa el incremento de la violencia juvenil en Somoto con la migración de las mujeres (GF3). En la mayoría de informantes la asociación migración-pandillas está presente. Este testimonio de un participante de uno de los grupos focales es elocuente:

Se corta esa unidad. Los chavalos que son adolescentes ya piensan andar en cosas como pandillas, porque muchos chavalos que ahora andan en vagancia es porque sus padres andan emigrando. Varios chavalos que les mandan bastante dinero y se compran bastantes cosas.

También el actual alcalde, Wilson Montoya, en el video-documental que se ha realizado en esta investigación, afirma que la tendencia a formar pandillas se da más entre hijos de mujeres migrantes. Por todo ello creemos que sería importante objetivar esa percepción en un estudio posterior.

A pesar de todos los problemas que se viven como consecuencia de la migración, los familiares han respondido, en los grupos focales, que merece la pena el esfuerzo.

\subsection{Otras consecuencias comunitarias y sociales}

No cabe duda de que el ingreso de remesas en una comunidad trae consigo ventajas que también benefician, indirectamente, a vecinos que no tienen familiares migrantes. El ejemplo más visible es la generación de empleos en el sector de la construcción debido a la edificación y mejora de viviendas. Somoto ha cambiado el aspecto externo en estos últimos años debido a este fenómeno.

Uno de esos cambios externos es la presencia de Ciber-cafés en el nuevo paisaje urbano de Somoto (EC2). Son utilizados tanto para el correo electrónico como para las llamadas telefónicas. El fin de semana es el momento más utilizado, según se reconoce en el grupo focal de adolescentes, aunque también señalan que eventualmente puede darse comunicación durante la semana.

Entre los beneficios indirectos en la dinamización de otros sectores, se conoce cómo las remesas han ayudado hasta a los mandaderos. En una investigación para El Nuevo Diario, Luis Lira, habitante de Totogalpa, cuenta que por hacer mandados, 
algunos familiares de migrantes le pagan al mes entre 214 y 428 córdobas (Aguilera, 2010c).

Normalmente las consecuencias de la migración son analizadas en términos individuales o familiares, pero entre los efectos negativos que el fenómeno migratorio comporta para la comunidad suelen pasar desapercibidos resultados que a largo plazo son adversos. En el caso que nos ocupa, donde hemos visto el elevado número de maestras que emigran, un efecto posible será la pérdida de calidad en la enseñanza de las escuelas debido al continuo recambio con maestras jóvenes. Se les priva a los niños de la experiencia acumulada de la maestra. El delegado departamental del Ministerio de Educación en Nueva Segovia, profesor Rolando Olivas, se refiere a este recambio de maestras, en una entrevista en El Nuevo Diario: "Ellas exponen que se van porque tienen deudas y no pueden sostenerlas. Así que optan por esa solución. ¿Qué hacemos nosotros? Echamos mano de los recién graduados de magisterio para ubicarlos en las plazas que ellas dejan" (Aguilera, 2010a).

Es difícil hacer un balance neto entre los efectos negativos y los positivos del fenómeno migratorio en Somoto, pues esto depende del punto de vista del actor implicado. No pensará lo mismo el que ha perdido su casa al hipotecarla, que el que ha logrado mejorar su vivienda. Así mismo, nos quedaría por investigar todo el campo de las remesas sociales, en las que se incluyen las nuevas ideas, comportamientos e identidades que provoca la migración, muchas veces a largo plazo. Sin embargo, la investigación sí permite hacer unas recomendaciones que vayan en la línea de una mejoría tanto en la situación de las mujeres migrantes como de un aprovechamiento más social y político de este fenómeno migratorio.

\section{Conclusiones y recomendaciones}

\subsection{Para mejorar la situación de las mujeres somoteñas en España}

- Es importante que el Estado nicaragüense no renuncie a tratar el tema migratorio en los Acuerdos y Tratados internacionales bilaterales o regionales. La Unión Europea y Estados Unidos han logrado que en las negociaciones de sus Tratados de Libre Comercio con Centroamérica (CAFTA con Estados Unidos y Acuerdo de Asociación con Unión Europea) no entre el tema migratorio, siendo como es un tema crucial en la relación de nuestra región con ellos. Esto se debe de hacer en alianza con otros países y con la sociedad civil de los países que acogen a nuestros migrantes. En ese aspecto, sería deseable que los hermanamientos se hicieran conscientes de que la solidaridad ha de tener un componente político importantísimo. La convalidación de títulos universitarios, los convenios para el reconocimiento de las cotizaciones a la Seguridad Social en ambos países, o la participación electoral, son sólo algunos de los puntos de una agenda política migratoria impostergable.

- Entre las políticas públicas del Estado ha de figurar la promoción de consulados y oficinas de atención al migrante. Es de esperar que los 
consulados en España -el más cercano a San Sebastián es el consulado de Bilbao- no sólo sirvan para las tramitaciones de documentos, sino para ejercer el cabildeo en los cambios que mejoren la situación de los migrantes. Para facilitar la cercanía de consulados, se sugiere la conversión de los consulados nacionales en consulados del CA-4, es decir, aprovechar los consulados de Guatemala, Honduras, El Salvador y Nicaragua, para que atiendan desde ellos a los nacionales de los cuatro países. Es una propuesta que el Servicio Jesuita para Migrantes ha sugerido anteriormente para beneficio de la migración centroamericana en Estados Unidos (Rocha, 2010, p.273). En España, la población nicaragüense ha mostrado su decepción y sus críticas por la lentitud de los trámites en la Embajada nicaragüense, que cuenta con tan sólo cinco funcionarios para atender una demanda de servicios que se ha multiplicado enormemente ya que en cuatro años se ha pasado de 15,000 nicaragüenses a 90,000, según declara el embajador, Augusto Zamora, en El Nuevo Diario (Rodríguez Rojas, 2011).

- Es necesario conocer los resquicios y oportunidades que las leyes europeas y españolas permiten, a pesar de todo el movimiento restrictivo y criminalizador de la migración que se vive en Europa. Particularmente interesante para el carácter femenino de la migración, que nos compete en esta investigación, es el nuevo Borrador del Reglamento de Ley Orgánica de Extranjería que el 8 de febrero de 2011 se ha presentado en España. La reforma hecha a la Ley Orgánica de Extranjería (2009) exigía un nuevo Reglamento. Ese Borrador incluye en el Título V ("Residencia por circunstancias excepcionales") un nuevo capítulo (Capítulo 2: "Víctimas de violencia de género" $)^{5}$ que contempla la residencia temporal y el trabajo para mujeres víctimas de la violencia de género, con protección que se extiende a los hijos, en caso de que los hubiera.

- El apoyo público a las asociaciones de migrantes debe de ser no sólo económico sino sobre todo político y técnico para que manejen los temas jurídicos y administrativos que pueden beneficiarles. Lograr empoderar a esas asociaciones, de modo que puedan ser facilitadoras de búsqueda de empleo, al mismo tiempo que interlocutoras reconocidas de cara a las políticas públicas tanto de los países de acogida como de origen, se convierte en una prioridad estratégica. Sería deseable que la sostenibilidad económica sea autónoma, para que los Estados tengan simplemente una función subsidiaria, y evitar las cooptaciones partidarias. Estas asociaciones han de ser también un cauce privilegiado de formación en temáticas como la defensa de sus derechos, la valoración y autoestima

5 "Borrador del Reglamento de la Ley Orgánica 4/2000, sobre derechos y libertades de los extranjeros en España y su integración social, tras su reforma por Ley Orgánica 2/2009". http://es.scribd.com/doc/48422411/ Borrador-del-reglamento-de-la-ley-de-extranjeria 
como mujeres, el apoyo psicosocial y los grupos de autoayuda. Los casos mostrados anteriormente de cooperativas de trabajo doméstico o de trabajo en acompañamiento a personas, que ya existen en el País Vasco, deberían de servir de modelo para que las migrantes nicaragüenses mejoren sus condiciones laborales. Las cooperativas dan seriedad a los contratos, responden por el buen desempeño de la trabajadora, ayudan con formación profesional y humana, evitan los abusos y, si los hay, los denuncian de forma más eficaz.

- Es importante el fortalecimiento de las alianzas en España con organizaciones de solidaridad, de la Iglesia y de ONGs de apoyo a los derechos de los y las migrantes. En particular, el derecho al reagrupamiento familiar, defendido especialmente desde organizaciones de Iglesia como Caritas, es clave en un fenómeno que muestra signos de permanencia a largo plazo, si no indefinida.

- Sería deseable una continuación de esta investigación, limitando su focalización a las dos problemáticas principales que se han señalado en el país de destino: la situación del trabajo doméstico y el esclarecimiento de la nebulosa que hay alrededor de las inciertas redes de trata de personas.

\subsection{Para la comunidad de origen}

- Promover las asociaciones de migrantes y su reconocimiento a todos los niveles de participación ciudadana, en comités de desarrollo local y nacional, así como la facilitación de su inversión social en las comunidades de origen por medio de diversas modalidades ya experimentadas en otros países.

- Es importante profundizar las investigaciones locales sobre las consecuencias psico-sociales de la migración en la infancia y juventud, enfocadas a prevenir y corregir los comportamientos y prácticas disfuncionales. Incluso si las acciones y políticas tuvieran posibilidades limitadas de incidencia, el conocimiento serviría para información de futuros migrantes y su mejor valoración de las consecuencias de su decisión de migrar.

- Por ello, se sugiere que una investigación posterior se focalice en las consecuencias de la "migración parental" en la infancia y juventud de Somoto.

- Comenzábamos este informe con una canción del somoteño Carlos Mejía Godoy, y lo terminamos con otra, intentando unirnos así al sentimiento de los que esperan el regreso de esas mujeres migrantes que, como la Teresita de "Ticuantepe sin vos", se fueron del pueblo y dejaron una gran tristeza: 
"Mirá que horrible está, Ticuantepe sin vos,

las casitas bonitas, sin vos, Teresita

qué tristes se ven”.

Y es que, aunque la migración haya logrado levantar “casitas bonitas”, esas mujeres somoteñas sueñan con habitarlas junto con sus familias. Muchos sueñan con recibirlas:

"Si decides volver me tenés que avisar, con violines y flores, sediento de amores, te voy a esperar".

\section{Anexos}

\section{Anexo 1. El trabajo doméstico en España}

En el documento "De la casa a la mesa del diálogo social", el Servicio Jesuita para Migrantes de España recoge las reflexiones y vivencias compartidas en torno al empleo doméstico, durante unos talleres realizados en varias ciudades de España y un seminario realizado el 22 de septiembre de 2010.

La discriminación que el Régimen Especial supone para la trabajadora doméstica queda en evidencia por estas diferencias que el documento recoge de un pliego de propuestas de 2009 del UN-INSTRAW (Instituto Internacional de investigaciones y capacitación de las Naciones Unidas para la promoción de la mujer) (SJM-España, 2010, p.4).

\begin{tabular}{|l|l|l|}
\hline & $\begin{array}{l}\text { Régimen Especial de } \\
\text { Empleadas de Hogar } \\
\text { Real Decreto } \\
1414 / 1985 \\
\text { (según modalidades: } \\
\text { internas o externas) }\end{array}$ & \\
\hline Contrato & Escrito u oral & Escrito \\
\hline $\begin{array}{l}\text { Jornada diaria } \\
\text { máxima }\end{array}$ & $\begin{array}{l}9 \text { horas } \\
\text { (16 horas en el caso } \\
\text { de las internas) }\end{array}$ & 9 horas \\
\hline $\begin{array}{l}\text { Descanso entre } \\
\text { jornadas }\end{array}$ & $\begin{array}{l}8 \text { horas internas } \\
10 \text { horas externas }\end{array}$ & 12 horas \\
\hline $\begin{array}{l}\text { Descanso } \\
\text { semanal }\end{array}$ & $\begin{array}{l}36 \text { horas continuadas } \\
\text { o no }\end{array}$ & 36 horas continuadas \\
\hline
\end{tabular}




\begin{tabular}{|l|l|l|}
\hline Salario & $\begin{array}{l}\text { Mínimo legal y } \\
\text { posibilidad de } \\
\text { descuento del 45\% en } \\
\text { especie }\end{array}$ & $\begin{array}{l}\text { Mínimo legal y posibilidad de } \\
\text { descuento del 30\% en especie }\end{array}$ \\
\hline Pagas extra & $\begin{array}{l}\text { 2 pagas extra anuales } \\
\text { de 15 días }\end{array}$ & 2 pagas extra anuales de 30 días \\
\hline $\begin{array}{l}\text { Protección de } \\
\text { la maternidad }\end{array}$ & $\begin{array}{l}\text { No existe despido } \\
\text { nulo }\end{array}$ & $\begin{array}{l}\text { Nulidad del despido durante el } \\
\text { embarazo }\end{array}$ \\
\hline Enfermedad & $\begin{array}{l}\text { Baja retribuida desde } \\
\text { día 29 }\end{array}$ & Baja retribuida desde día 3 \\
\hline $\begin{array}{l}\text { Desempleo y } \\
\text { prejubilación }\end{array}$ & $\begin{array}{l}\text { No hay prestación } \\
\text { por desempleo ni } \\
\text { prejubilación }\end{array}$ & $\begin{array}{l}\text { Sí hay prestación por desempleo y } \\
\text { prejubilación }\end{array}$ \\
\hline $\begin{array}{l}\text { Cotizaciones } \\
\text { a la Seguridad } \\
\text { Social }\end{array}$ & $\begin{array}{l}\text { Cotización fija y } \\
\text { por cuenta de la } \\
\text { empleada si se trabaja } \\
\text { menos de 20 horas } \\
\text { semanales para el } \\
\text { mismo empleador; no } \\
\text { se cotiza si se trabaja } \\
\text { menos de 72 horas al } \\
\text { mes }\end{array}$ & $\begin{array}{l}\text { Cotización variable y por empleador; } \\
\text { obligación de cotizar desde la primera } \\
\text { hora }\end{array}$ \\
\hline $\begin{array}{l}\text { Preaviso de 7 días } \\
\text { (antigüedad menor a } \\
\text { un año); preaviso de } \\
\text { in días (antigüedad } \\
\text { mayor a un año) }\end{array}$ & $\begin{array}{l}\text { Preaviso de 30 días } \\
\text { indemnizización } \\
\text { cuando es justificado } \\
\text { de 7 días/límite } \\
\text { máximo de 6 } \\
\text { mensualidades; } \\
\text { indemnización } \\
\text { cuando es } \\
\text { improcedente de 20 } \\
\text { días/límite de } 12 \\
\text { mensualidades }\end{array}$ & $\begin{array}{l}\text { Indemnización cuando es justificado } \\
\text { de } 30 \text { días/límite 12 mensualidades; } \\
\text { indemnización cuando es improcedente } \\
\text { de 45 días/límite 42 mensualidades }\end{array}$ \\
\hline
\end{tabular}




\section{Anexo 2. Convenio OIT sobre trabajo doméstico adoptado el 16 de junio de 2011}

Al concluir la redacción final de este artículo hemos recibido la grata noticia de la adopción, en la 100 a Conferencia de la OIT, en Ginebra, del tan esperado Convenio sobre el Trabajo Decente para las Trabajadoras y los Trabajadores Domésticos, así como una Recomendación, que se convertirán en el Convenio 189 de la OIT y la Recomendación 201, desde que en 1919 se fundó la organización. Estas normas laborales internacionales, que protegerán a entre 53 y 100 millones de trabajadores domésticos en el mundo, son históricas porque, según declara el Director General de la OIT, Juan Somavia, "por primera vez llevamos el sistema de normas de la OIT a la economía informal". Y añade que "esto tendrá repercusiones relacionadas con las migraciones y con la igualdad de género”, pues alrededor del 83 por ciento de estos trabajadores son mujeres o niñas, y muchas son migrantes, asegura el comunicado de la OIT (2011).

El 16 de junio los delegados aprobaron el Convenio por 396 votos a favor, 16 votos en contra y 63 abstenciones, y la Recomendación que lo acompaña por 434 votos a favor, 8 votos en contra y 42 abstenciones. El Convenio tiene rango de Tratado internacional vinculante para los Estados que lo ratifiquen, y entrará en vigor doce meses después de la fecha en que las ratificaciones de dos Miembros hayan sido registradas por el Director General.

Serán reconocidos los mismos derechos que a otros trabajadores: horas de trabajo razonables, compensación de las horas extraordinarias (art. 12), descanso semanal de al menos 24 horas consecutivas, límite a los pagos en especie (art. 12), seguridad social (art. 14), información clara sobre los términos y las condiciones de empleo, salario mínimo, remuneración no discriminatoria por razón de sexo (art. 11), respeto a los principios y derechos fundamentales en el trabajo, incluyendo los de libertad sindical y negociación colectiva (art. 3), etc.

La relación de este Convenio con la migración es explícita ya desde las consideraciones introductorias. La Convención señala que "el trabajo doméstico sigue siendo infravalorado e invisible y que lo realizan principalmente las mujeres y las niñas, muchas de las cuales son migrantes o forman parte de comunidades desfavorecidas, y son particularmente vulnerables a la discriminación con respecto a las condiciones de empleo y de trabajo, así como a otros abusos de los derechos humanos". Se previene contra el fenómeno de la trata, ya que exige el derecho de la trabajadora doméstica a conservar los documentos de viaje y de identidad (art. 9 c).

El Convenio indica repetidamente la necesidad de consultas con las organizaciones representativas de los trabajadores domésticos. Una de nuestras recomendaciones señala la importancia de promover este tipo de organizaciones.

Fuente: (OIT, 2011) 


\section{Referencias bibliográficas}

Aguilera, A. (2010a, 25 de julio). Migración nica a España tiene rostro femenino. El Nuevo Diario. Recuperado el 6 de abril de 2011, de http://www.elnuevodiario. com.ni/especiales/79699

Aguilera, A. (2010b, 26 de julio). Sueño español o una aventura sin paracaídas. El Nuevo Diario. Recuperado el 5 de abril de 2011, de http://www.elnuevodiario. com.ni/especiales/79762

Aguilera, A. (2010c, 27 de julio). Rebeldía de hijos por años de no ver a la mamá migrante. El Nuevo Diario. Recuperado el 5 de abril de 2011, de http://www. elnuevodiario.com.ni/especiales/79844

Aparicio Gómez, R. \& Tornos Cubillo, A. (2010). Las asociaciones de inmigrantes en España. Una visión de conjunto. Madrid: Observatorio Permanente de la Inmigración, Ministerio de Trabajo e Inmigración.

Aragón, W. (2011, 25 de octubre). Cooperante vasca limpia su imagen. La Prensa. Recuperado el 13 de noviembre de 2011, de http://www.laprensa.com. ni/2011/10/25/ambito/78065

Cae banda que prostituía en España a mujeres nicas. (2011, 30 de octubre). La Prensa. Recuperado el 13 de noviembre de 2011, de http://www.laprensa. com.ni/2011/10/30/hechos/78682\#.Tq6vKPQm3ZU

Comunidad Señorío de Jesús, Victoria (2008, octubre). Nicaragua y el P. Victoriano Arizti. Comunidad Señorío de Jesús. Recuperado el 7 de abril de 2011, de http:// sdjvitoria.org/content/view/55/66/

Cooperante vasca escandaliza con compras de propiedades en Somoto. (2011, 28 de febrero). El Nuevo Diario. Recuperado el 13 de noviembre de 2011, de http:// www.elnuevodiario.com.ni/nacionales/95800

Dramática suerte de inmigrante. (2009, 9 de marzo). Bolsa de Noticias. Recuperado el 5 de abril de 2011, de http://www.bolsadenoticias.com.ni/2009/marzo/09/ opinion.htm

Esgueva Gómez, A. (1996). La Mesoamérica nicaragüense: Documentos y comentarios. Managua: Universidad Centroamericana.

Fe y Alegría - Bolivia (2010). Madurar sin padres: Los efectos de la migración de los progenitores en el desempeño escolar de los niños y adolescentes en Bolivia. La Paz: Entreculturas.

Foro-Industrial.com (2011). SMI 2010: Salario Minimo Interprofesional 2010 España. Recuperado el 7 de marzo de 2011, de http://www.foro-industrial. com/2009/11/smi-2010-salario-minimo-interprofesional-2010-espana/

Indígenas chorotegas de Nicaragua censarán su población. (2011, noviembre). Univisión. Recuperado el 15 de febrero de 2011, de http://www.univision. com/contentroot/wirefeeds/noticias/8359467.shtml

Instituto Nacional de Información de Desarrollo [INIDE]. (2005). Encuesta de Hogares sobre Medición del Nivel de Vida - EMNV. Base de datos en soporte CD. Managua: Autor.

Lapitz, X. (2011, 1 de marzo). Cooperación sentimental. Diario de Noticias. Recuperado el 8 de marzo de 2011, de http://diariodenoticias.com/2011/03/01/politica/ euskadi/cooperacion-sentimental 
Las clave del entramado entre Lasarte y Somoto: Un repaso cronológico para entender toda la actividad de Ana Urchuegía en Somoto y las ayudas de cooperación. (2011, 6 de marzo). Noticias de Guipúzcoa. Recuperado el 8 de marzo de 2011, de http://www.noticiasdegipuzkoa.com/2011/03/06/politica/euskadi/lasclaves-del-entramado

Las remesas de los inmigrantes se mantienen en 2010 tras dos años de caídas. (2011). Europa Press. Recuperado el 7 de abril de 2011, de http://www. europapress.es/economia/noticia-remesas-inmigrantes-mantienen-2010-dosanos-caidas-20110331141313.html

Nagore, G. (2011a, 29 de marzo). Ana Urchueguía comparecerá el próximo martes en el Parlamento. Noticias de Navarra, Recuperado el 2 de abril de 2011, de http://www.noticiasdenavarra.com/2011/03/29/politica/euskadi/anaurchueguia-comparecera-el-proximo-martes-en-el-parlamento

Nagore, G. (2011b, 6 de abril). Urchueguía reconoce que fue un error comprar una finca a la ONG que tutelaba. Noticias de Guipúzcoa. Recuperado el 7 de abril de 2011, de http://www.noticiasdegipuzkoa.com/2011/04/06/politica/ euskadi/urchueguia-reconoce-que-fue-un-error-comprar-una-finca-a-la-ongque-tutelaba

Nagore, G. (2011c, 7 de junio). La nueva mayoría de Lasarte-Oria emprenderá acciones legales por el caso Urchueguía. Noticias de Guipúzcoa. Recuperado el 19 de junio de 2011, de http://www.noticiasdegipuzkoa.com/2011/06/07/ politica/euskadi/la-nueva-mayoria-de-lasarte-oria-emprendera-accioneslegales-por-el-caso-urchueguia

OIM \& UNICEF-Guatemala (2011). Encuesta sobre Remesas 2010, Protección de la niñez y adolescencia, Guatemala: Autor. Recuperado el 7 de abril de 2011, de http://www.iom.int/jahia/Jahia/media/press-briefing-notes/pbnAM/ cache/offonce/lang/es? entryld=29438

Organización Internacional del Trabajo [OIT]. (2009). Trabajo decente para los trabajadores domésticos. Ginebra: Autor.

Organización Internacional del Trabajo [OIT]. (2011, junio). La 100ª Conferencia de la OIT adoptó normas laborales para proteger a entre 53 y 100 millones de trabajadores domésticos en el mundo. Comunicado OIT del 16 de junio de 2011. Recuperado el 18 de junio de 2011, de http://www.ilo.org/ilc/ILCSessions/100thSession/ media-centre/press-releases/WCMS_157892/lang-es/index.htm

Requena Aguilar, A. (2010, enero). Las empleadas del hogar tendrán más derechos. Público. Recuperado el 7 de abril de 2011, de http://www.publico.es/ dinero/288436/las-empleadas-del-hogar-tendran-mas-derechos

Rocha, J. L. (2006). Una región desgarrada, Dinámicas migratorias en Centroamérica. San José: Servicio Jesuita para Migrantes.

Rocha, J. L. (2010). Expulsados de la globalización. Managua: Instituto de Historia de Nicaragua y Centroamérica - INHCA-UCA.

Rodríguez Rojas, L. (2011, 17 de junio). Amargas críticas a embajada nica en España. El Nuevo Diario. Recuperado el 17 de junio de 2011, de http://www. elnuevodiario.com.ni/nacionales/105213-amargas-criticas-a-embajada-nicaespana

Salario Mínimo Interprofesional: La cuantía retributiva mínima. (2010). Salario 
mínimo. Recuperado el 25 de febrero de 2011, de http://www.salariominimo. es/.

Sánchez Paz, J. M. (2008). La experiencia de las mujeres víctimas de trata en América Central y República Dominicana y la actuación de las instituciones. San José: OIM - Costa Rica.

Secretaría de Estado de Inmigración y Emigración, Ministerio de Trabajo e Inmigración. (2011a). Extranjeros residentes en España a 31 de diciembre de 2010. Recuperado el 7 de abril de 2011, de http://extranjeros.mtin.es/es/ InformacionEstadistica/Informes/Extranjeros31Diciembre2010/index.html

Secretaría de Estado de Inmigración y Emigración, Ministerio de Trabajo e Inmigración. (2011b). Extranjeros residentes en España a 31 de diciembre de 2010. Recuperado el 7 de abril de 2011, de http://extranjeros.mtin.es/ es/InformacionEstadistica/Informes/Extranjeros30Junio2011/Archivos/ Tablas_PR_30062011.pdf

Secretaría de Estado de Inmigración y Emigración, Ministerio de Trabajo e Inmigración. (2011c). Extranjeros residentes en España a 30 de junio de 2011. Recuperado el 30 de agosto de 2011, de http://extranjeros.mtin.es/es/ InformacionEstadistica/Informes/Extranjeros30Junio2011/Archivos/ Principales_Resultados_30062011.pdf

Sirias, T. (2008, 28 de julio). Tráfico con nicas "esclavas" a España. El Nuevo Diario. Recuperado el 5 de abril de 2011, de http://www.elnuevodiario.com.ni/ nacionales/22648

SJM-España. (2010). De la casa a la mesa del diálogo social: Reflexiones y vivencias compartidas en torno al empleo doméstico. Propuestas de actuación. Recuperado el 6 de abril de 2011, de http://www.centroellacuria.org/imgx/sjm/de\%20 la\%20casa\%20a\%20la\%20mesa.pdf 